\title{
Chapter 20 \\ Changes in Attitudes Towards Textbook Task Modification Using Confrontation of Complexity in a Collaborative Inquiry: Two Case Studies
}

\author{
Kyeong-Hwa Lee
}

\begin{abstract}
This study examined how two middle school mathematics teachers changed from being reluctant to modify tasks in mathematics textbooks to having positive attitudes about textbook task modification. In order to successfully coordinate a curriculum revision with the textbooks they use, mathematics teachers need to be able to use their in-depth understanding of the intentions of both the revision and textbooks to modify and implement tasks appropriately. The two middle school teachers' cases in this study showed that it is possible to change teachers' negative attitudes about modifying tasks in mathematics textbooks if they explicitly understand the complexity in mathematics teaching and go through a sequence of activities that help them understand the revised curriculum in detail, interpret and modify textbook tasks, and implement the modified tasks and reflect on their implementation.
\end{abstract}

Keywords Mathematics textbook - Textbook task modification Complexity map · Collaborative inquiry • Professional development

\subsection{Introduction}

Teacher researcher- or teacher-led inquiry communities have been increasingly viewed as promising for professional growth and development of theory and practice in mathematics education (Lin and Cooney 2001; Dowling 2013; Jaworski 2003; Slavit and Nelson 2010; Robutti et al. 2016; Goodchild 2008; Goodchild et al. 2013). Researchers have reported that teachers both deepen content knowledge and pedagogical knowledge by learning ways of teaching and develop their understanding of how to facilitate students' conceptual understanding through collaborative work with their colleagues and researchers (e.g., Sullivan et al. 2012;

K.-H. Lee $(\bowtie)$

Seoul National University, Seoul, South Korea

e-mail: khmath@snu.ac.kr

(C) The Author(s) 2018

G. Kaiser et al. (eds.), Invited Lectures from the 13th International Congress

on Mathematical Education, ICME-13 Monographs,

https://doi.org/10.1007/978-3-319-72170-5_20 
Cooper et al. 2006). However, with the popularity of community approaches, pitfalls have also arisen such as limited local school resources, shortages of qualified teachers in distressed areas, and stress related to performance on high stakes testing (Ledoux and McHenry 2008). In addition, a number of tensions produced from the complex nature of relationships among members in communities have suggested that one cannot be purely optimistic about such collaborative work (Martin et al. 2011). Therefore, there is a need to unpack the tensions and complexities involved in community approaches along with the learning opportunities among teachers and researchers by recognizing the genuine perspectives and needs of teachers (Schwarz 2001).

Textbook modification is a common procedure used in collaborative approaches by teachers and researchers for professional development (Bao and Stephens 2013; Boston and Smith 2011; Zaslavsky 1995). Through textbook modification, teachers can learn how to redesign textbook tasks and how to teach mathematics differently. In order to successfully coordinate a curriculum revision with the textbooks they use, mathematics teachers need to be able to use their in-depth understanding of the intentions of both the revision and textbooks in order to modify and implement tasks appropriately. However, studies have shown that a number of mathematics teachers merely follow textbooks as they are written (Manouchehri and Goodman 1998; Choe and Hwang 2004, 2005). A deeper understanding is needed of the reason that mathematics teachers place textbooks in a rather fixed position of high authority. Professional development programs giving opportunities for teachers to reflect on this passiveness towards textbook modification may help teachers to consider textbooks to be a type of curriculum material that can be evaluated, interpreted, and redesigned prior to and during lessons (Drake and Sherin 2006; Lloyd 1999; Remillard 2005). In this study, teachers were invited to co-learning activities with the researcher that focused on textbook task modification (TTM) for professional development. Although the community was initiated by the researcher, the teachers participated voluntarily in the whole collaboration and all members had equal status (Hospesovà et al. 2006). To recognize the teachers' genuine perspectives on and needs for TTM, teacher narrative analysis was used. This article will describe and discuss why and how two middle school mathematics teachers who participated and had a voice in all phases of the research process (Sullivan et al. 2012; Goodchild 2008; Jaworski 2003) changed their initial attitudes about modifying tasks in mathematics textbooks from negative to positive.

\subsection{Learning by Collaborative Work on TTM}

A professional learning community (PLC) of teachers and educators facilitates teacher and researcher learning through collaboration, conversation, and inquiry (Jaworski 2003; Goodchild et al. 2013). The ways in which the participants in a PLC interact is closely linked to the roles they play within the community (Robutti et al. 2016). The three elements of practice-engagement, imagination, and 
alignment of participant - can be employed as essential norms in a PLC (Jaworski 2003) for lesson study. Firstly, members of a community can be engaged in the activities of analyzing and modifying textbook tasks and applying and reflecting on the modified tasks (Bao and Stephens 2013; Boston and Smith 2011; Coe et al. 2010). The purpose of analyzing textbook tasks is to gain insights into their intended mathematical and pedagogical meaning through revealing specific learning goals and making distinctions between task features, such as context-based and open-ended tasks (Sullivan et al. 2012). In addition, predicting student misconceptions and errors can be done at this stage. Finally, possible dimensions and possible ranges of variation (Watson and Mason 2006) of concepts, procedures, or representations embedded implicitly or explicitly in tasks can be described using task analysis. Based on these detailed analyses, we move to the modification stage, in which we make judgments on modifications in detail. We prepare supplementary tasks to help those students who cannot begin the given task or those who complete tasks in a very short time. Applying this stage includes not only implementation of modified tasks but also improvisational adaptation of tasks based on in-the-moment decisions in reaction to students' responses.

Secondly, imagination, which requires participants in the community to disengage by moving back and looking at the engagement through the eyes of an outsider (Wenger 1998, p. 185), can be considered in collaborative work between teachers and researchers. In order to take a step back and look at the big picture of teachers' engagement related to textbook task use, understanding teachers' perspectives by asking the following questions is useful. Why do you think teachers should analyze textbook tasks? What does it mean to analyze? What are the criteria and methods for analyzing? What was the most important thing you learned from the experience of analysis? Have you had any experience in modifying textbook tasks? When, why, and how did you do any modification? How did you understand the results of implementing modified tasks? What were your main concerns both when you were modifying textbook tasks and after you implemented the modified tasks? What was the most important thing you learned from the experience of modifying and implementing the tasks?

When answering the above questions, teachers can regard themselves as subjects who interpret and modify textbook tasks (Remillard 2005) and not as subjects who use textbook tasks with few or no modifications. The above questions are to recall and describe teachers' perceptions of the complexity of textbook use in their everyday classrooms. Teachers' answers to these questions may be represented as a map showing key issues and concerns; this will be called a complexity map in this study. A complexity map is defined as a diagram that is made using teachers' answers to the above questions and teachers' perceptions of complexity in textbook use. A complexity map is an ongoing process that makes it possible to examine teachers' concerns and understand the indirect effects that influence the direction and degree of task modification and implementation. In other words, a complexity map can be a communication tool that teachers initiate or lead the creation of that represents various components and the relationships among those components that teachers have perceived while they were analyzing, modifying, and implementing 
textbook tasks. A complexity map by an individual teacher can reveal a part of a subjective scheme, a kind of mental framework by which objectively given structures of information such as tasks and narratives in textbooks are understood and interpreted (Otte 1986). A complexity map may vary with respect to educational environments, teaching cultures, and value systems. Mathematical emphasis, referring to the mathematics knowledge and practices that are valued (Remillard et al. 2014, p. 739), may differ among teachers who have different perceptions of the complexities in textbook use (Ben-Peretz 1990; Heaton 2000; Sherin and Drake 2009). Furthermore, teachers' different complexity maps may have different influences on students' learning opportunities (Schmidt 2007; Valverde et al. 2002; Grouws and Smith 2000; Stein et al. 2007).

By constructing a complexity map as a communication tool in collaborative works, critical alignment (Goodchild et al. 2013) can be pursued. Teachers and researchers can create a special synergy by means of critical alignment mediated by complexity maps as suggested in Goodchild et al. (2013). One possible aim for both teachers and researchers in a PLC for textbook modification can be engagement of students in mathematics learning by modifying textbook tasks. The other possibility is doing research and drawing implications on textbook task use in classrooms. Teacher-researcher collaboration to achieve these aims can be facilitated by critical alignment between both participants. Complexity maps can be viewed as a set of problems to be solved or set of constraints to be overcome by collaborative treatments. We can see a complexity map as a window to look at practices from teachers' perspectives. Using a complexity map, we can invite teachers to reflect on their current practices and to highlight partial or general complexity when considering TTMs. If critical alignment between practice- and research-based awareness in teaching with textbook tasks can be developed and rooted in the learning community, then knowledge can grow in practice.

\subsection{Mathematics Curriculum and Mathematics Textbooks in Korea}

The place that curriculum and textbooks take in mathematics education can vary from country to country. In the Korean context, the curriculum and textbooks are regarded as having high authority by teachers, parents, and students. The mathematics curriculum in Korea is developed by a committee that is sanctioned at the national level. Mathematics curriculum reform has been conducted based on discussions about the objectives, content, and methods of mathematics education. When this study was conducted, we used the curriculum that was revised in 2009 (Ministry of Education, Science, and Technology [MEST] 2009). In the 2009 Curriculum, mathematical problem solving, communication, and reasoning were considered to be crucial process standards for nurturing mathematical creativity, and it was strongly recommended that these three aspects be realized in teaching 
and learning (MEST 2009). In addition, the 2009 Curriculum suggested finding and exploring real-life contexts that are familiar to students and accepting student intuition and an informal approach. The 2009 Curriculum's structure has five sections: characteristics, objectives, content, teaching and learning methods, and evaluation. In the characteristics section, school mathematics is described as a subject that deals with mathematical concepts, principles, and rules to be explored in various contexts; develops logical thinking; cultivates the ability to observe and interpret various phenomena; and develops an understanding of how to use various methods to solve problems. MEST (2009) puts particular emphasis on the development of mathematical literacy:

The in-depth understanding and application of mathematical concepts, including problem-solving ability, are essential in learning diverse content successfully and are also necessary to increase one's skills and ability to solve problems as a democratic citizen. Moreover, mathematical knowledge and thinking methods act as an intellectual driving force in the development of human civilization and are necessary in the rapidly changing information-based society. (p. 5)

The objectives for the three school levels, primary, middle, and high school, are set by integrating perspectives from relevant research studies as well as the aims and the requests of the noosphere (Chevallard and Bosch 2014). For example, the objective for middle school mathematics is

to obtain the basic knowledge and understand the functions of mathematics, to cultivate the ability to think mathematically and communicate in order to create practical solutions to social and natural phenomena and problems, and to cultivate a positive attitude toward mathematics. (MEST 2009, pp. 8-9)

Even terms and notations that should be included in textbooks and lessons are presented in the curriculum. In addition to teaching and learning methods, recommendations for didactic transposition of content are presented. For example, in the functions section for seventh grade, the following recommendations are included: (a) Use a daily-life context where one quantity changes as another quantity changes and (b) teach the concept of functions at an intuitive level. In the evaluation section, a great deal of emphasis is put on conducting assessments in order to provide useful cognitive and definitive suggestions that can help students' learning and well-rounded development and improve teaching practices. Considering the level of students' mathematical knowledge is also explicitly mentioned, and abiding by the content presented in the curriculum documents is suggested. A variety of types of evaluation, such as formative and summative evaluations, is suggested as well. This systematically organized intended curriculum influences Korean mathematics textbook development and mathematics teaching in classrooms.

Textbook writers make an effort to realize the reform ideas prescribed in the curriculum by following its terms and the notations, instructions for teaching specific content areas, and aspects to be emphasized in evaluation. In general, Korean textbooks are written based on thorough interpretation of the content, the teaching and learning methods, and the evaluation policies in the intended 
curriculum. Therefore, even though there are various kinds of secondary school textbooks in Korea, they have a lot in common in many aspects. The coverage and the depth of content areas, teaching and learning strategies, and assessment systems in textbooks are almost the same. Therefore, studies have shown that it is very natural for teachers follow the national curriculum and their textbooks in planning lessons (Choe and Hwang 2004, 2005). Teachers' tendency to follow the intended curriculum explains the difficulty of opening a discussion on the necessity of TTM in professional development programs about TTM. In this study, making each mathematics teacher's complexity perception explicit is used as a strategy to open a discussion on the necessity of TTM.

\subsection{Research Context}

As a large part of research project, 88 middle school mathematics teachers first participated in a six-hour professional development program on textbook-task use. Seventeen of these teachers then voluntarily participated in a second professional development program on TTM that lasted eight months. At the beginning of this advanced professional development program, a survey was administered to examine the teachers' experiences with and attitudes toward TTM where they were asked to choose between three items: (1) I have experience with modifying textbook tasks, (2) I am not willing to modify textbook tasks, and (3) I want to learn more about modifying textbook tasks if there is any follow-up program. Based on the survey results, two teachers who had experienced TTM but had negative attitudes toward it were selected for the purpose of this study in order to examine why these teachers had negative attitudes toward TTM, the reasons behind their negative attitudes, and why and how they changed their perspective on TTM over time. The two teachers, Euna and Miyeong, were both female. Euna was in her early 30s and had six years of teaching experience but did not have any textbook-writing experience. She taught a seventh grade class consisting of approximately 34 students at a large, low-achieving public middle school for boys located in a large metropolitan city. The other teacher, Miyeong, was in her mid-40s, had 17 years of teaching experience, and had textbook-writing experience. Miyeong taught an eighth grade class of approximately 33 students at a large, low-achieving public school for boys and girls located in a large metropolitan city. Miyeong was widely recognized as an expert teacher and was actively involved in enhancing students' interest in mathematics.

The data were collected in three ways: teachers' narratives, which were used to get insights about their perceptions and beliefs (Connelly and Clandinin 1990; Schwarz 2001); discussions; and classroom observations of their mathematics classrooms. First, teachers were asked to write free narratives on the following topics: previous TTM experiences; a brief explanation about why they were not willing to do TTM; key roles, affordances, and constraints of textbook tasks; complexities in task use, teaching, and learning; tensions and dilemmas experienced 
in teaching and participating in PD programs; and what they learned from TTM and its implementation. Teachers' narratives were used in discussion meetings as prompts. Discussion meetings were conducted 12 times from March to October. After selecting key issues to be discussed in these meetings, the meetings were facilitated to discuss the issues systematically. Another source of data was classroom observation. Euna's four lessons, where the topics were the concept of a function, graphs of functions, and applications of functions, were observed. Miyeong's five lessons, where the topics were events, relative frequency, the concept of probability, and probability calculation, were also observed.

\subsection{Findings}

The relationships between teachers and the curriculum seem to be relatively simple in the Korean mathematics education context, as mentioned in the earlier section. In particular, the two teachers, Euna and Miyeong, clearly presented their negative attitude to TTM in the beginning. The reasons for their prior thoughts on TTM will be reported first. Then, how complexity maps showing the teachers' recognition of their practices were drawn and utilized over PLC meetings will be described. The significant tensions and challenges faced by the teachers and how the teachers changed their attitudes to TTM can provide interesting insights into the ways in which the teachers incorporated the reform principles prescribed in the revised curriculum into their teaching practices.

\subsubsection{Rationales for Negative Attitudes Toward TTM}

Both teachers in this study had negative attitudes toward TTM at the beginning of the PLC activity. Their participation in the prior workshop for six hours and their volunteering to participate in the PLC meetings for eight months showed that they did not just blindly follow textbooks and that they were at least somewhat interested in TTM. Euna viewed textbooks as effective tools for teaching mathematics, a view similar to those of the teachers in Choe and Hwang's studies $(2004,2005)$. She used textbooks without modifications because she felt that textbook tasks (a) are effective in deepening students' mathematical understanding, (b) are systematically sequenced and have appropriate scope, and (c) reflect new visions and recent research trends in the mathematics curriculum and teaching and learning of mathematics. Her positive evaluation of textbooks can be attributed to her trust in the process of textbook development and its authors in Korea. In describing her trust in textbooks, she said:

Textbooks are usually written by a team of mathematicians, mathematics educators, and experienced mathematics teachers. They must incorporate new visions, appropriate content, 
and new teaching and thinking methods into the textbook they are writing. Why not follow the textbook? It is an optimal solution [emphasis added] for teaching and learning mathematics in our environment.

The idea of optimal solution that Euna described is closely related to the way of organizing content in Korean mathematics textbooks. Korean mathematics textbooks are structured in a deductive way in the sense that their basic structure starts with the definition and ends with its application via some explanations, with worked out examples and drills in the meantime. Before the body of the content begins, an interesting opening is provided that gives a context in which the learning content can be related to what students are familiar with.

In summary, Euna's negative attitudes toward TTM can be attributed to her satisfaction with current textbooks and her belief that it is more effective to follow textbooks. The dilemma Euna faced is associated with her perception of unchanging practices with the revised curriculum. For her, an optimal solution has nothing to do with the newly emphasized competences such as communication, reasoning, and problem solving. She was invited to reconsider what would be optimal for her interpretations and implementations of textbook tasks in order to find another optimal solution.

Similar to Euna, Miyeong also trusted textbooks. However, she provided different reasons for her negative attitudes toward TTM. Having 17 years of teaching experience, she was widely recognized as an expert teacher. Being sensitive to curriculum revisions, she fully understood what had been revised in the curriculum. She had rich experience with modifying textbook tasks. Despite all of this, she was reluctant to modify textbook tasks because she thought that it was much easier to design new tasks rather than modify the existing tasks in textbooks:

There is a saying that "revolution is easier than reform." Likewise, I prefer to design new tasks instead of TTM. I am free to use various contexts and knowledge from a variety of fields such as film, travel, finance, and history when designing new tasks. However, this only applies to extra classes, such as work done after finishing units or after-school programs, but not to regular classes. TTM is not easy to implement because we need to cover the limited range of concepts and procedures that are contained in the curriculum. If the advantages of TTM for teaching specific content in the curriculum are clear, it would be okay.

Even if textbook tasks were to be modified, it would be important for Miyeong to maintain the original learning goals and content as intended in the textbooks; however, it was difficult to create learning opportunities that were better than the textbook tasks. The reason for this limitation was that she was concerned with being able to attain the original learning goal and was sensitive to potential changes to what can be learned using modified tasks. The rationale behind her negative attitudes toward TTM included: (a) TTM does not guarantee good learning and teaching and (b) TTM is a challenging and risky job. While explaining that TTM is a challenging and risky job, Miyeong mentioned cases where the main focus of instruction is on non-mathematical issues, for example, cases that mainly focus on students' interests. 
It is noteworthy that both teachers had negative attitudes toward TTM because they trusted textbooks more than their unsuccessful TTM. The rationales behind the teachers' negative attitudes toward TTM show that one should not interpret merely following textbooks as a signal of teachers' resistance to being independent of textbook use. Instead, teachers' resistance to TTM can be viewed as their faithful implementation of the curriculum. Having identified the fact that the two teachers greatly value faithful implementation of curriculum, we naturally moved to discuss the complexities faced by the teachers and were able to draw complexity maps.

\subsubsection{Complexities Perceived by the Two Teachers}

Faithful implementation of the curriculum has proved challenging, since the mathematical emphases and pedagogical approaches included in the curriculum materials are difficult to carry out (Lloyd 1999; Remillard 2005). Moreover, Korean mathematics teachers are under intense pressure to raise or maintain students' test scores while at the same time realizing the reform ideas described in the curriculum documents (Lee 2010; Park 2004). Although reasonable rationales for their negative attitude to TTM were discussed, the two teachers recognized the necessity of TTM, which led them to volunteer to participate in the PLC on TTM. The initial complexity maps were constructed based on the teachers' perceptions about complexity in teaching. Among various fragmentary components, those that were perceived first became the discussion topics and were reflected in the initial complexity maps. For example, Euna expressed her uncomfortable feeling about the fact that some students did their homework from cram schools during mathematics classes or independent study time. It was also difficult for her to see that her students' parents mainly focused on their children's test scores. These issues came out in Euna's narratives and during discussion meetings and were reflected in her initial complexity map. In her narratives and PLC meetings, Miyeong focused more on potential mathematical meanings and the structures of particular concepts that should be highlighted in her classes. The two teachers' perceptions about complexity in their teaching practices were different, which might explain their different understandings of the challenges and dilemmas of TTM (Leder et al. 2006; Goldin et al. 2011; Gates 2006).

Table 20.1 shows the categories of the types of complexity that Euna and Miyeong initially perceived: student-related complexity (SRC), mathematics-related complexity (MRC), and external complexity (EC). Several differences in their experiences, including teaching experience and experience with writing textbooks, could be connected to the difference in the initial complexity that each teacher perceived. Miyeong was able to recognize the complexities in her implementation well and competently explain each complexity. On the other hand, Euna's order of priorities was EC, SRC, and MRC, and she rarely recognized the relationship among the complexities. Unlike Miyeong, Euna expressed difficulties with teaching mathematics and spent a considerable amount of time expressing 
such difficulties as complexities and making the connection to task modification. Before Euna discussed issues with Miyeong, Euna was not sure how to reflect some of the complexities in TTM. For instance, regarding the issue of cram schools, Euna was very concerned about the interruptions made by students who attended cram schools but did not come up with specific solutions, whereas Miyeong identified the issue of cram schools as "bad habits in learning mathematics." This indicates that cooperation with colleagues, particularly with more experienced teachers, is important in developing mathematics teachers' expertise, as previous research has evidenced (Garet et al. 2001; Desimone et al. 2002).

Euna frequently mentioned cram schools, which she identified as one of the external complexities. Considering that approximately $30 \%$ of her students attended cram schools and learned content in advance, Euna had difficulty in designing tasks and planning lessons for those students.

One thing I never feel easy about is the interruption made by the students who go to cram schools. They already know the content before I teach it. If these students dominate the dialogue among students by employing the mathematics concepts that are considered the learning goal, then other students lose learning opportunities. Inquiry-based learning is not easily pursued in this situation.

Teaching was also very complex for Euna because parents were very interested in and passionate about their children's education, and they tended to evaluate and supervise her teaching. Among SRCs, Euna mentioned the range in students' achievement levels most frequently. As curriculum revision had been conducted so frequently, Euna felt the pressure to change things in her practice. This indicates that she was trying to understand the revised curriculum and reflect it in her practice. Another MRC is evaluation. Assessment-focused mathematics education has been characterized as one of the main features of mathematics education in East

Table 20.1 Initial complexities that Euna and Miyeong individually perceived

\begin{tabular}{|c|c|c|}
\hline Type of complexity & $\begin{array}{l}\text { Complexities Euna initially } \\
\text { perceived }\end{array}$ & $\begin{array}{l}\text { Complexities Miyeong initially } \\
\text { perceived }\end{array}$ \\
\hline Student related (SRC) & $\begin{array}{l}\text { - A wide range of achievement } \\
\text { - Negative attitude } \\
\text { - Passive attitude }\end{array}$ & $\begin{array}{l}\text { - A wide range of achievement } \\
\text { - Negative attitude } \\
\text { - Changing students } \\
\text { - Bad habits in learning } \\
\text { mathematics } \\
\text { - Learning anxiety pressure }\end{array}$ \\
\hline $\begin{array}{l}\text { Mathematics related } \\
\text { (MRC) }\end{array}$ & $\begin{array}{l}\text { - Frequently changed } \\
\text { curriculum } \\
\text { - Assessment }\end{array}$ & $\begin{array}{l}\text { - Unfamiliar terminology } \\
\text { - Hierarchy of mathematics } \\
\text { - Abstract mathematics } \\
\text { - Not differentiated curriculum } \\
\text { - Assessment }\end{array}$ \\
\hline External (EC) & $\begin{array}{l}\text { - Cram schools } \\
\text { - High level of parents' } \\
\text { enthusiasm } \\
\text { - Large class size }\end{array}$ & - Cram schools \\
\hline
\end{tabular}


Asia (e.g., Park 2004; Leung 2001), and Euna was also very concerned about preparing students for assessments while teaching. She commented that she taught in ways that "emphasized the content and form of knowledge reflected in assessments but did not focus as much on knowledge that would not be assessed." This may have influenced her task designing and lesson planning, which made her teaching complex. Miyeong had more factors related to MRC.

For Miyeong, teaching was complex because of issues involving the nature of mathematics, such as "the hierarchy of mathematics" and "abstract mathematics." Other factors such as "unfamiliar terminology," "not differentiated curriculum," and "assessment" were complexities related to the limitations of school mathematics. In terms of SRC, beyond "a wide range of achievement" and "negative attitudes (toward mathematics and mathematics learning)" that Euna perceived, Miyeong thought that the complexity was attributed to "different students," "bad habits in learning mathematics," and "learning anxiety or pressure." Among these, Miyeong provided the following explanation for "different students":

We never have the same students; on the contrary, teachers need to be prepared to satisfy new students every year. The students I have this year are quite different from those I taught last year. Hence, I had to learn what and how they learned and can learn in my classes day by day. I had to develop how to teach mathematics in many ways.

The changes in the cognitive aspects of students mentioned above were not the only difficulties Miyeong experienced. She said in the later discussion that she had difficulties with task design and lesson planning in terms of students' different dispositions and attitudes toward mathematics. For instance, she said that "students in the past waited quietly, but students nowadays do not wait at all, so it is difficult to include problems that require in-depth investigation from the students." When Miyeong explained about "bad habits in learning," she associated it with cram schools and assessment. For example:

Many students seek recipes for solving problems with the goal of getting high scores on the tests. Thus, creating tasks that do a good job of enhancing the students' learning is very important. Otherwise, students may develop bad habits, such as depending on strange recipes without understanding the necessary mathematics behind them. Cram schools are places where students learn such irrelevant strategies. I have tried to tackle this issue in different ways, but it is not easy to resolve.

Whenever Miyeong referred to "bad habits in learning," Euna thought that this was related to her EC and agreed with Miyeong. For example, Euna said, "Right, I had students who bragged about weird methods learned from cram schools, but I could understand them," and emphasized the interruptions made by these students.

Even though the initial complexity maps were not clear in meaning, they played roles in forming discourses between the teachers and the researcher about practices. It was especially helpful for me as a researcher to understand the teachers' circumstances and the practices they used in teaching mathematics. This was effective in decreasing the asymmetry between the teachers and the researcher that is generally caused by the researcher presenting certain theories or results of previous studies (Goodchild 2008) and achieving equal status between practitioners and 
theorists (Hospesovà et al. 2006). Discussions that were dominated by discourses initiated by the teachers rather than by the researcher led to teachers having greater curiosity about theories and previous studies. For example, there were many discussions led by Miyeong about abstraction in mathematics and the structure of mathematical knowledge, and at the end of these discussions, the teachers asked questions about mathematics teaching-learning theory and related research results.

Although teachers did not reach a level where they were finding and discussing theories and research results themselves, they tended to appreciate each component in a complexity map from a theoretical standpoint as they related them to TTM. They also tried to understand the relationships between various components in the complexity map. In addition, teachers attempted to connect what they understood from various research results to analyzing and modifying textbook tasks. These collaborative activities led teachers to deepen complexities of teaching and to utilize complexity maps as a tool to form a productive discourse that can be helpful in analyzing and modifying textbook tasks. It provided teachers with opportunities to take some theoretical perspectives into consideration for resolving their teaching dilemmas. Gradually, the two teachers began to play researcher roles in the sense that they contributed to the elaboration of some research questions to be examined using implementations of their own TTMs. The two teachers became deeply involved in the collaborative inquiry, which resulted in the development of profound content knowledge and pedagogical content knowledge (Jaworski 2007; Darling-Hammond and Richardson 2009).

It is worth mentioning that the two teachers found the necessity for and ways of implementing TTM after a few discussions about their complexity maps. They started talking about their unsuccessful TTM experiences and tried to see those from a distance in order to link them to a particular theoretical perspective that would give them ideas for improvements. By introducing relevant studies, the teachers could relate to their previous experiences with TTM and the researcher identified potential research questions to collaboratively tackle in the later stages. In the meantime, the teachers determined the affordances and constraints of textbook tasks they wanted to highlight or overcome in the classroom. For example, Euna said,

Textbook tasks are ideal for average or low-achieving students because they introduce the standard method. They specify the detailed steps, so I do not need to provide any extra explanation. However, they are limited in that they do not consider that various students are at different achievement levels. I can try TTM when targeting students from different achievement levels.

She further tried to find the affordances and constraints of textbook tasks based on her perception of the instructional reality (Zhao et al. 2006):

Textbook tasks are too simple and stereotyped to deepen conceptual understanding. As many students use the secret recipes, they think that they are good at mathematics as long as they are dealing with textbook tasks. I would like to design tasks that cannot be solved by their methods but provide rich conceptual understanding. 
Fig. 20.1 The shared complexity map

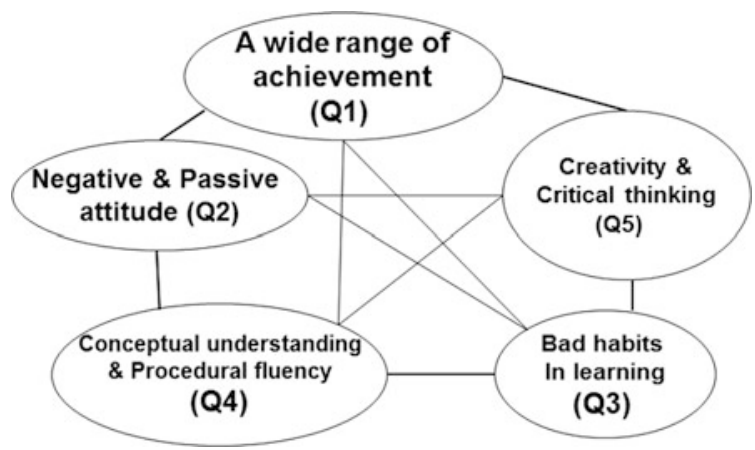

Both teachers emphasized that it was a very meaningful experience to develop expertise while considering a complexity map and analyzing textbook tasks. Opportunities to discuss the initial complexities that each teacher perceived, to share teaching practices, and to analyze the affordances and constraints of textbook tasks served to develop expertise for both teachers. This is evidence of closing the gap between theory and practice in mathematics teaching and learning based on teacher-researcher collaborations. In the end, all members in the PLC constructed a shared complexity map to tackle five core questions (see Fig. 20.1):

Q1. How can we consider a wide range of student achievement?

Q2. How can we consider students' negative and passive attitudes towards mathematics and mathematics learning?

Q3. How can we change students' bad learning habits using TTM?

Q4. How can we enhance conceptual understanding with procedural fluency using TTM?

Q5. How can we engage students in creative and critical thinking using TTM?

\subsubsection{Two Teachers' Use of the Shared Complexity Map in the TTM Process}

Euna tried TTM on 109 tasks. Of the 109 modified tasks, 35 (about 32\%) had a cognitive level higher than the original tasks, 66 (about 61\%) maintained the same cognitive level as the original tasks, and 8 (about 7\%) had a lower cognitive level than the original tasks. Euna was developing a sensibility about changes in the cognitive demands of a task by implementing TTM over time. Her main focus was to increase the participation of various students, especially those with low achievement. This became a turning point for her and helped her become more active in implementing TTM. 
I will never forget the moment when I discovered Sucheol working very hard on a task I was able to offer him using TTM. He used to be like a ghost in the previous classes. At this moment, however, he was so visible to everyone, including me. I was like, like... I cannot express the emotion I felt at that moment. It was one of the best moments in my teaching career. Since then, I have had no doubt about the value of TTM.

Euna's TTM process included considering SRC explicitly and implementing it first and then implicitly and indirectly considering EC and MRC (see Fig. 20.2).

Miyeong modified 43 textbook tasks using the process of first modifying the task herself and then doing a second modification after a discussion. Miyeong additionally modified 74 textbook tasks by herself without discussion. Of the 117 modified tasks, 82 (about 70\%) had higher cognitive demands than the originals, 26 (about 22\%) maintained the original cognitive demands, and 9 (about 8\%) had lower cognitive demands than the originals. Miyeong was very sensitive to the changes of cognitive demands of tasks at the beginning of TTM. Unlike Euna, who focused on SRC, Miyeong mainly considered MRC, consequently increasing the cognitive demands of the tasks beyond those in the textbook. Euna consistently identified SRC, but Miyeong first considered MRC and made opportunities for low-achieving students to participate if possible. Miyeong's turning point in cultivating a positive attitude toward TTM was quite different from Euna's:

It was quite striking for me to see doubtful contexts or prompts included in textbook tasks. For example, the warm-up task for teaching probability using a 14-faced die was far from the fundamental idea of experimental probability. The first prompt was rolling the die 20 times, which is irrelevant to the meaning of experimental probability. Doing this may provide an opportunity to think about the "law of large number," but that is not the focus in this unit. Suddenly I felt embarrassed, as I did not consider that ever before and just asked students to complete the table. Why that kind of prompt was there without proper intent and why did I just follow it? Why wasn't I aware of it?

Miyeong's TTM process included considering MRC first and then SRC while explicitly considering EC. Figure 20.3 illustrates this process and its dynamics.

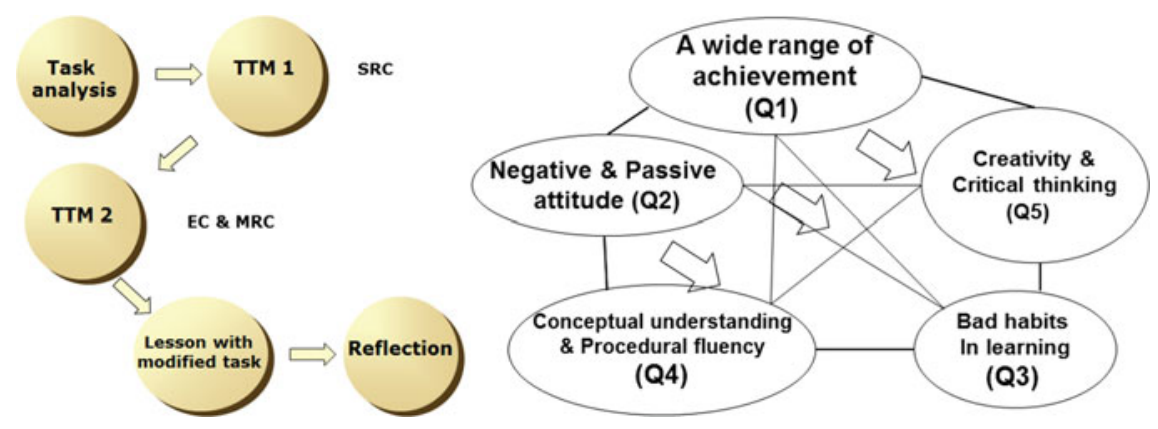

Fig. 20.2 Euna's TTM process and dynamics in the shared complexity map 


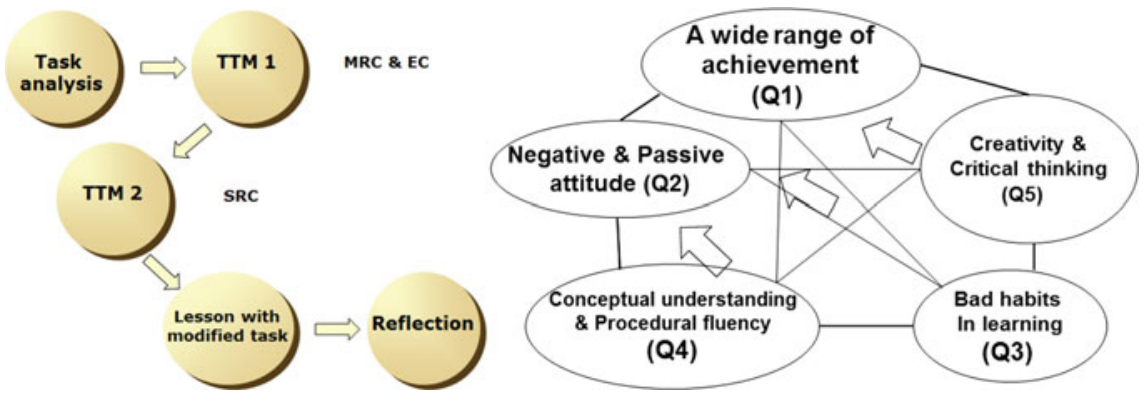

Fig. 20.3 Miyeong's TTM process and dynamics in the shared complexity map

\subsection{Conclusion}

Unlike what has been shown in previous studies (e.g., Drake and Sherin 2006), the two middle school teachers in this study trusted the contents and structure of MEST-authorized mathematics textbooks rather than having been influenced by the way they learned and experienced mathematics when they were students. The teachers were concerned that TTM itself did not promote effective lessons or reform lessons and that it would sometimes result in bad modifications that were worse than textbook tasks. In order to successfully coordinate the revised curriculum with the textbooks they use, mathematics teachers need to be able use their in-depth understanding of the intentions of both the revision and textbooks in order to modify and implement tasks appropriately. The two middle school teachers' cases in this study showed that it is difficult to change teachers' passive attitudes about modifying tasks in mathematics textbooks unless they go through a sequence of activities that help them understand the revised curriculum in detail, interpret and modify textbook tasks, and implement the modified tasks and reflect on their implementation.

Instead of making teachers learn theoretical concepts or the results of previous studies that are provided to them by a researcher, this study progressed by encouraging the teachers to verbalize the complexities they perceived, recognize them as problems, and find solutions through modifying textbook tasks. This process was very challenging because the teachers and the researcher sometimes either had different meanings for the same terms or used ambiguous terms. Over time, however, examining the complexity became helpful in clarifying the common goal of modifying tasks for effective instruction and finding their implementation strategies. This shows that mathematics teachers can play an active and key role in constructing and operating a learning community with other mathematics teachers. In other words, the use of a complexity map played a significant role in critical alignment of the intent and the implementation of class using the modified textbook tasks, as shown by Goodchild et al. (2013). 
From their experiences with modifying textbook tasks, implementing modified tasks, and then reflecting on what they had done, mathematics teachers had an opportunity to understand the essence of school mathematics deeply. In this study, I did not focus on the development of the teachers' mathematical knowledge for teaching specifically. However, from the discussions about modifying the tasks and the actual modification, I was able to gain evidence of substantial development. This should be closely examined in future studies. In this study, the focus was on changing mathematics teachers' prejudices about task modification, especially their absolute trust in textbook tasks. Teachers learned that it is necessary to modify textbook tasks according to situations that they face, even though the textbook tasks were developed based on previous studies. Moreover, when they implemented modified tasks in their class, they learned how to observe whether they were helpful in revealing the essence of school mathematics and whether the lesson was facilitated efficiently. The two teachers in this study mentioned that for a long time they had recognized the importance of reflecting on lessons, but they did not know what aspects of lessons should be reflected upon or how to reflect. They stated that through participating in this professional development program, they had learned why they should think about the textbook tasks when they prepared lessons, how and in what ways they could modify the tasks, how to observe when they implement the modified tasks in class, and how they could draw improvement ideas for the next class. The professional development in this study changed the asymmetric discourse structure between teachers and researcher to a symmetric one that was different in quality from ones that add several theories or results of studies to the teachers' previous perspective. This kind of professional development is significant since it has transformative potential (Price 2001), in that teachers can continue to reflect and improve their reality for themselves.

\section{References}

Bao, L., \& Stephens, M. (2013). Using a modified form of lesson study to develop students' relational thinking in years 4, 5 \& 6. In V. Steinle, L. Ball, \& C. Bardini (Eds.), Mathematics education: Yesterday, today and tomorrow (Proceedings of the 36th Annual Conference of the Mathematics Education Research Group of Australasia) (pp. 74-81). Melbourne: MERGA.

Ben-Peretz, M. (1990). The teacher-curriculum encounter: Freeing teachers from the tyranny of texts. USA: SUNY Press.

Boston, M. D., \& Smith, M. S. (2011). A 'task-centric approach' to professional development: Enhancing and sustaining mathematics teachers' ability to implement cognitively challenging mathematical tasks. ZDM, 43(6-7), 965-977.

Chevallard, Y., \& Bosch, M. (2014). Didactic transposition in mathematics education. In S., Lerman (Ed.), Encyclopedia of mathematics education (pp. 170-174). The Netherlands: Springer.

Choe, S.-H., \& Hwang, H.-J. (2004). A study on implementation of the seventh mathematics curriculum at the elementary school level. School Mathematics, 6(2), 213-233.

Choe, S.-H., \& Hwang, H.-J. (2005). A study on the seventh national curriculum at the secondary school level. School Mathematics, 7(2), 193-219. 
Coe, K., Carl, A., \& Frick, L. (2010). Lesson study in continuing professional teacher development: A South African case study. Academica, 42(4), 206-230.

Connelly, F. M., \& Clandinin, D. J. (1990). Stories of experience and narrative inquiry. Educational Researcher, 19(5), 2-14.

Cooper, T. J., Baturo, A., \& Grant, E. (2006). Collaboration with teachers to improve mathematics learning: pedagogy at three levels. In Proceedings of the 30th Conference of the International Group for the Psychology of Mathematics Education (Vol. 2, pp. 361-367) Prague, Czech Republic: Charles University.

Darling-Hammond, L., \& Richardson, N. (2009). Research review/teacher learning: What matters. Educational Leadership, 66(5), 46-53.

Desimone, L. M., Porter, A. C., Garet, M. S., Yoon, K. S., \& Birman, B. F. (2002). Effects of professional development on teachers' instruction: Results from a three-year longitudinal study. Educational Evaluation and Policy Analysis, 24(2), 81-112.

Dowling, D. (2013). Hungary for calculation: Developing approaches to calculation in the new curriculum using Hungarian methodology as our inspiration (NCETM CTP4213). Sheffield: NCETM. Retrieved from https://www.ncetm.org.uk/files/20365123/CTP4213+Final+Report. pdf.

Drake, C., \& Sherin, M. G. (2006). Practicing change: Curriculum adaptation and teacher narrative in the context of mathematics education reform. Curriculum Inquiry, 36(2), 153-187.

Garet, M. S., Porter, A. C., Desimone, L., Birman, B. F., \& Yoon, K. S. (2001). What makes professional development effective? Results from a national sample of teachers. American Educational Research Journal, 38(4), 915-945.

Gates, P. (2006). Going beyond belief systems: Exploring a model for the social influence on mathematics teacher beliefs. Educational Studies in Mathematics, 63(3), 347-369.

Goldin, G. A., Epstein, Y. M., Schorr, R. Y., \& Warner, L. B. (2011). Beliefs and engagement structures: Behind the affective dimension of mathematical learning. ZDM, 43(4), 547-560.

Goodchild, S. (2008). A quest for 'good' research. In B. Jaworski \& T. L. Wood (Eds.), (2008). The mathematics teacher educator as a developing professional (pp. 201-220). The Netherlands: Sense Publishers.

Goodchild, S., Fuglestad, A. B., \& Jaworski, B. (2013). Critical alignment in inquiry-based practice in developing mathematics teaching. Educational Studies in Mathematics, 84(3), 393 412.

Grouws, D. A., \& Smith, M. S. (2000). NAEP findings on the preparation and practices of mathematics teachers. In E. A. Silver \& P. A. Kenney (Eds.), Results from the seventh mathematics assessment of the national assessment of educational progress (pp. 107-139). Reston, VA: National Council of Teachers of Mathematics.

Heaton, R. M. (2000). Teaching mathematics to the new standard: Relearning the dance (Vol. 15). New York: Teachers College Press.

Hospesovà, A., Machàckovà, J., \& Tichà, M. (2006). Joint reflection as a way to cooperation between researchers and teachers. In Proceedings of the 30th Conference of the International Group for the Psychology of Mathematics Education (Vol. 1, pp. 99-103). Prague, Czech Republic: PME.

Jaworski, B. (2003). Research practice into/influencing mathematics teaching and learning development: Towards a theoretical framework based on co-learning partnerships. Educational Studies in Mathematics, 54(2-3), 249-282.

Jaworski, B. (2007). Theory and practice in mathematics teaching development: Critical inquiry as a mode of learning in teaching. Journal of Mathematics Teacher Education, 9(2), 187-211.

Leder, G. C., Pehkonen, E., \& Törner, G. (Eds.). (2006). Beliefs: A hidden variable in mathematics education? (Vol. 31). Berlin: Springer Science \& Business Media.

Ledoux, M. W., \& McHenry, N. (2008). Pitfalls of school-university partnerships. The Clearing House: A Journal of Educational Strategies, Issues and Ideas, 81(4), 155-160.

Lee, K. H. (2010). Searching for Korean perspective on mathematics education through discussion on mathematical modeling. Research in Mathematics Education, 20(3), 221-239. 
Leung, F. K. (2001). In search of an East Asian identity in mathematics education. Educational Studies in Mathematics, 47(1), 35-51.

Lin, F. L., \& Cooney, T. (Eds.). (2001). Making sense of mathematics teacher education. Berlin: Springer Science \& Business Media.

Lloyd, G. M. (1999). Two teachers' conceptions of a reform-oriented curriculum: Implications for mathematics teacher development. Journal of Mathematics Teacher Education, 2(3), 227-252.

Manouchehri, A., \& Goodman, T. (1998). Mathematics curriculum reform and teachers: Understanding the connections. The Journal of Educational Research, 92(1), 27-41.

Martin, S. D., Snow, J. L., \& Franklin Torrez, C. A. (2011). Navigating the terrain of third space: Tensions with/in relationships in school-university partnerships. Journal of Teacher Education, 62(3), 299-311.

Ministry of Education, Science, and Technology. (2009). Mathematics curriculum. Seoul, Korea.

Otte, M. (1986). What is a text? In B. Christiansen, A. G. Howson, \& M. Aile (Eds.), Perspectives on mathematics education (pp. 173-203). The Netherlands: Springer.

Park, K. M. (2004). Factors contributing to Korean students' high achievement in mathematics. In Korea sub-commission of ICMI. The report on mathematics education in Korea (pp. 85-92).

Price, J. N. (2001). Action research, pedagogy and change: The transformative potential of action research in pre-service teacher education. Journal of Curriculum Studies, 33(1), 43-74.

Remillard, J. T. (2005). Examining key concepts in research on teachers' use of mathematics curricula. Review of Educational Research, 75(2), 211-246.

Remillard, J. T., Harris, B., \& Agodini, R. (2014). The influence of curriculum material design on opportunities for student learning. ZDM, 46(5), 735-749.

Robutti, O., Cusi, A., Clark-Wilson, A., Jaworski, B., Chapman, O., Esteley, C., et al. (2016). ICME international survey on teachers working and learning through collaboration. ZDM, 48 (5), 651-690.

Schmidt, W. H. (Ed.). (2007). Characterizing pedagogical flow: An investigation of mathematics and science teaching in six countries. Berlin: Springer Science \& Business Media.

Schwarz, G. (2001). Using teacher narrative research in teacher development. The Teacher Educator, 37(1), 37-48.

Sherin, M. G., \& Drake, C. (2009). Curriculum strategy framework: Investigating patterns in teachers' use of a reform-based elementary mathematics curriculum. Journal of Curriculum Studies, 41(4), 467-500.

Slavit, D., \& Nelson, T. H. (2010). Collaborative teacher inquiry as a tool for building theory on the development and use of rich mathematical tasks. Journal of Mathematics Teacher Education, 13(3), 201-221.

Stein, M. K., Remillard, J., \& Smith, M. S. (2007). How curriculum influences student learning. In F. K. Lester (Ed.), Second handbook of research on mathematics teaching and learning (Vol. 1, pp. 319-369).

Sullivan, P., Clarke, D., \& Clarke, B. (2012). Teaching with tasks for effective mathematics learning (Vol. 9). Berlin: Springer.

Valverde, G. A., Bianchi, L. J., \& Wolfe, R. G. (2002). According to the book: Using TIMSS to investigate the translation of policy into practice through the world of textbooks. Berlin: Springer.

Watson, A., \& Mason, J. (2006). Mathematics as a constructive activity: Learners generating examples. UK: Routledge.

Wenger, E. (1998). Communities of practice: Learning, meaning, and identity. Cambridge: Cambridge University Press.

Zaslavsky, O. (1995). Open-ended tasks as a trigger for mathematics teachers' professional development. For the Learning of Mathematics, 15(3), 15-20.

Zhao, Q., Visnovska, J., Cobb, P., \& McClain, K. (2006). Supporting the mathematics learning of a professional teaching community: Focusing on teachers' instructional reality. In Annual Meeting of the American Educational Research Association Conference, San Francisco, CA. 
Open Access This chapter is licensed under the terms of the Creative Commons Attribution 4.0 International License (http://creativecommons.org/licenses/by/4.0/), which permits use, sharing, adaptation, distribution and reproduction in any medium or format, as long as you give appropriate credit to the original author(s) and the source, provide a link to the Creative Commons license and indicate if changes were made.

The images or other third party material in this chapter are included in the chapter's Creative Commons license, unless indicated otherwise in a credit line to the material. If material is not included in the chapter's Creative Commons license and your intended use is not permitted by statutory regulation or exceeds the permitted use, you will need to obtain permission directly from the copyright holder.

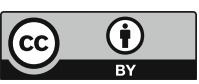

